\title{
A study on the relationship between academic adjustment and global mobility of foreign students in Taiwan
}

Huang, Chin-Yi $\$

Graduate Student, Graduate Institute of Educational Leadership and Development, Taiwan (chinyi0818@gmail.com)

\section{Lin, Shih-Ling}

Professor, Graduate Institute of Educational Leadership and Development, Taiwan (lead0001@mail.fju.edu.tw)

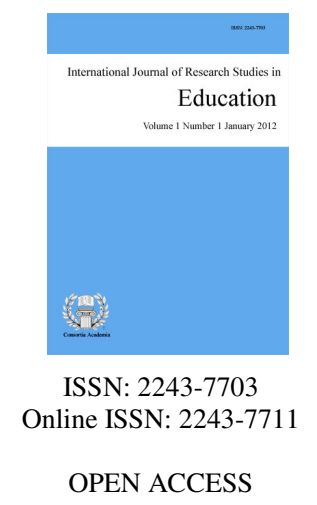

Received: 9 March 2020

Available Online: 3 July 2020

Revised: 20 June 2020 DOI: $10.5861 /$ ijrse.2020.5805

\section{Abstract}

The purpose of this study is to explore the relationship between academic adjustment and global mobility of foreign students. First of all, this study starts by conducting a literature review in order to establish a theoretical base. According to the research purposes and the questions, the researcher put forward, a questionnaire was developed in order to investigate foreign students' academic adjustment and global mobility. A total of 316 valid questionnaires were collected in this study, with 191 males and 125 females. Further applications and suggestions are proposed in accordance with the relevant results. This study finds significant differences in global mobility between the groups of males and females, especially in communication and in professional competence. In communication, the males are better than the females. Moreover, in Professional Competence, the males are also better than the females. The males are confident of applying the professional aptitudes in the future. There are significant differences in the ability to find solutions and the service satisfactions in different genders. According to the results of this study, the suggestions and applications, the researcher put forward as a reference for educational administration agencies, schools, and further studies in the future.

Keywords: foreign student; academic adjustment; global mobility; professional competence; service satisfaction 


\section{A study on the relationship between academic adjustment and global mobility of foreign students in Taiwan}

\section{Introduction}

The twenty-first century is an era of globalization. With the rise of the concept of a global village, we recognize that strengthening international interactions and promoting the well-being of all humankind is our responsibility as global citizens. In response to the waves of global mobility, the migration of university students across national borders has become a key indicator for the implementation of internationalization in higher education. This study defines global mobility as students with the unobstructed ability to move and study abroad. The benefits of global mobility include nurturing international professionals, developing global perspectives, immersing in local cultures, and enriched lives that come from experiencing different cultures.

While placing a greater emphasis on global mobility, universities worldwide have recently exerted much effort in the inbound and outbound students. The effect of globalization on higher education has been prominent since the early 1990s (Enders, 2004). This increase in the intake of international students has not only resulted in economic benefits, but also changed the ecologies of universities' structures, administrations and operations (Vickers \& Bekhradnia, 2007). It is crystal clear that global mobility is defined by a student's unobstructed ability to travel and study abroad. The advantages of global mobility include nurturing international professionals, opening global vision, immersing in the local culture, and enriching life that comes from experiencing a different culture.

According to the Ministry of the Interior (2019), the population of Taiwan reached a total of 23,588,932 at the end of 2018, with 11,876,000 females and 11,712,000 males. However, a significant risk factor for Taiwan's future is our low birthrate. According to the Ministry of Education (2019), higher education enrollment is expected to decrease from 273,000 in 2015 to 158,000 by 2028. This decrease will have a huge impact on the higher education system, with 20 to 40 universities estimated to be in danger of closing within the next five years, especially small and private universities in the suburbs. Hence, the sharp decline in Taiwan's university student population in recent years is a great problem for many universities.

In 2016, the government of Taiwan launched a national level "New Southbound Policy" which aims to shift the focus from past endeavors of one-way investing to building bilateral people-to-people links with Southeast and South Asian countries. Under President Tsai Ing-wen's administration, New Southbound Policy (NSP), Taiwan is increasingly turning its attention to students coming from Southeast Asia. Roughly 38,000 of nearly 118,000 international students enrolled at Taiwanese universities were from the Association of Southeast Asian Nations (ASEAN) countries, a perceivable increase from 28,000 in 2016 (Ministry of Education, 2019).

According to MOE Deputy Minister Chen Liang-gee, the government plans to allocate NT\$1 billion (US\$31.6 million) for projects proposed in the 2016 academic year, with more than 70 percent of this amount to be spent on the policy of attracting students from ASEAN and India. In this regard, Taiwan's Ministry of Education developed a three-year program (2017-2020) titled "Talent Cultivation between Taiwan and New Southbound Policy Countries" that is based on the New Southbound Policy guidelines and promotion program. The program emphasizes that Taiwan's government will not only provide more grants and scholarships to foreign students who are willing to study in Taiwan (i.e. an attracting strategy), but will also provide such financial aid to Taiwanese students who apply to go to other ASEAN countries for further education, internships, and many others (Yang, 2017).

More and more foreign students are choosing to study in Taiwan; the number of foreign students has continued to grow. However, there are also some obstacles that students from Southeast Asia have probably 
A study on the relationship between academic adjustment and global mobility of foreign students in Taiwan

encountered. First of all, the course design of Taiwan's universities ignores the gap between different languages. Although foreign students are asked to attend a basic Mandarin course, this training is not enough for them to handle other compulsory courses.

Moreover, the e-mails, announcements, group messages, and mobile applications developed by most of the campus' administrative units are mainly in the Mandarin language. Only a few administrative units, such as the Foreign Student Affairs Office and the Residential Counseling Office provide bilingual services. Foreign students who are proficient in Mandarin will be able to obtain the correct information, but for other Southeast Asian students, it remains a difficult task to understand the information they need.

With the increase of international students coming to Taiwan, foreign students studying abroad in Taiwan are demonstrating how life and learning adjustment and other related issues have gradually emerged. Foreign students from different countries and cultures must encounter many cultural and lifestyle adaptation problems when coming to Taiwan to study. As the recruitment of foreign students to study in Taiwan, it can really provide a good environment and space for foreign students to study and develop. Behind the generous scholarships, do we really care about the difficulties of foreign students coming to Taiwan to study, and are we able to provide appropriate assistance?

With this background, the purpose of this study is to explore the relationship between the academic adjustment and global mobility of foreign students. First of all, this study starts by conducting a literature review in order to establish a theoretical base. According to the research purposes and the questions I put forward, a questionnaire was developed in order to investigate foreign students' academic adjustment and global mobility. A total of 316 valid questionnaires were collected in this study, with 191 males and 125 females, respectively. Further applications and suggestions are proposed in accordance with the relevant results.

\section{Literature review}

\subsection{The overview of foreign students in Taiwan}

Globalization has profoundly influenced the social conditions and educational systems of countries around the world. The interrelationships between countries have formed a "global village". In the past decade, the number of Asian international students has soared exponentially around the world. Asian international students choose to study abroad, they seek to expand their global capabilities and learn more professional aptitudes. In doing so, they face a new environment that differs from their home countries. In Taiwan, a significant risk factor to our future is our low birthrate. This decrease will have a huge impact on the higher education system, with 20 to 40 universities estimated to be in danger of disappearing within five years, especially small and private universities in the suburbs.

The "New Southbound Policy" promotion plan is a new educational policy that that aims to attract students to study in Taiwan. As a result, the foreign student population in Taiwan is growing rapidly. However, only a few studies have focused on foreign students' academic adjustment and global mobility. According to the statistics of the Ministry of Education, the number of foreign students in public and private colleges and universities has increased from 30,509 in 2007 to 116,416 in 2016, and the number of foreign students who are officially studying for advanced degrees is 17,788 (National Academy for Educational Research, 2016).

It is obvious that our government actively promotes the relevant policies and subsidy programs for foreign students, and the major colleges and universities are more aggressive in visiting various countries to recruit foreign students and attracting high-caliber foreign students to study for advanced degrees or Mandarin language courses in Taiwan. According to Table 1, the number of foreign students in Asia in 2016 academic year was 14,327 and the number of students in 2018 was 24,773. Under the Government's active promotion of the "New Southbound Policy", the number of foreign students from Asia has increased by 10,446, showing a steady 
Huang, C.-Y., \& Lin, S.-L.

growth trend in recent years.

\section{Table 1}

2016-18 Academic year statistics on foreign and overseas students studying in Taiwan from 6 continents

\begin{tabular}{lcccccc}
\hline \multirow{2}{*}{ Academic year } & \multicolumn{2}{c}{2016 Academic year } & \multicolumn{2}{c}{ 2017 Academic year } & \multicolumn{2}{c}{ 2018 Academic year } \\
\cline { 2 - 7 } & $\begin{array}{c}\text { Foreign } \\
\text { students }\end{array}$ & $\begin{array}{c}\text { Chinese } \\
\text { Origin }\end{array}$ & $\begin{array}{c}\text { Foreign } \\
\text { students }\end{array}$ & $\begin{array}{c}\text { Chinese } \\
\text { Origin }\end{array}$ & $\begin{array}{c}\text { Foreign } \\
\text { students }\end{array}$ & $\begin{array}{c}\text { Chinese } \\
\text { Origin }\end{array}$ \\
\hline Asia & 14327 & 10465 & 17578 & 11184 & 24773 & 11608 \\
Oceania & 265 & 42 & 299 & 33 & 296 & 30 \\
Africa & 769 & 70 & 803 & 62 & 914 & 58 \\
Europe & 721 & 13 & 717 & 17 & 670 & 17 \\
North America & 1443 & 466 & 1480 & 432 & 1421 & 371 \\
South America & 263 & 121 & 287 & 117 & 315 & 112 \\
$\quad$ Total & 17788 & 11177 & 21164 & 11845 & 28389 & 12196 \\
\hline
\end{tabular}

Data source: from the Ministry of Education, International and cross-strait education Academic, department of the National College of

Education overseas students living information network https://ois.moe.gov.tw/web/fs/html/statisticsearchd.html

According to Table 2, Indonesia, Thailand, Malaysia and Vietnam, for example, were the four countries with the largest number of foreign students studying in Taiwan from ASEAN countries, with Malaysia holding the largest number (5,197 foreign students and 7,894 overseas students), with a total of 13,091. The total of foreign students studying in Taiwan that are from Indonesia was 7,347, ranking second. The total number of foreign students from Vietnam studying in Taiwan was also nearly 8,000, ranking third.

Table 2

2016-18 Statistics on foreign and overseas students studying in Taiwan from ASEAN 10 countries

\begin{tabular}{|c|c|c|c|c|c|c|}
\hline \multirow[b]{2}{*}{ Academic year } & \multicolumn{2}{|c|}{2016 Academic year } & \multicolumn{2}{|c|}{2017 Academic year } & \multicolumn{2}{|c|}{2018 Academic year } \\
\hline & $\begin{array}{l}\text { Foreign } \\
\text { students }\end{array}$ & $\begin{array}{c}\text { Chinese } \\
\text { Origin }\end{array}$ & $\begin{array}{l}\text { Foreign } \\
\text { students }\end{array}$ & $\begin{array}{c}\text { Chinese } \\
\text { Origin }\end{array}$ & $\begin{array}{l}\text { Foreign } \\
\text { students }\end{array}$ & $\begin{array}{c}\text { Chinese } \\
\text { Origin }\end{array}$ \\
\hline Indonesia & 1923 & 1208 & 2662 & 1401 & 5686 & 1661 \\
\hline Philippines & 180 & 32 & 236 & 36 & 451 & 44 \\
\hline Thailand & 544 & 240 & 635 & 212 & 769 & 186 \\
\hline Malaysia & 5044 & 7645 & 5449 & 7984 & 5197 & 7894 \\
\hline Singapore & 107 & 89 & 102 & 91 & 103 & 88 \\
\hline Brunei & 6 & 16 & 5 & 12 & 6 & 9 \\
\hline Viet Nam & 2807 & 358 & 3884 & 581 & 7058 & 796 \\
\hline Myanmar & 73 & 494 & 73 & 524 & 194 & 586 \\
\hline Cambodia & 8 & 0 & 13 & 0 & 67 & 0 \\
\hline Laos & 2 & 3 & 21 & 2 & 28 & 2 \\
\hline Total & 10694 & 10085 & 13080 & 10843 & 19559 & 11266 \\
\hline
\end{tabular}

Data source: from the Ministry of Education, International and cross-strait education Academic, department of the National College of Education overseas students living information network https://ois.moe.gov.tw/web/fs/html/statisticsearchd.html

\subsection{Foreign students' academic adjustment and global mobility}

Foreign students arrive in new countries to study, as well as learn how to adapt to different cultures and ways of life. They will certainly encounter difficulties when studying abroad. This is due to the lack of understanding of new cultural habits, and a lack of understanding of the cultural background of new countries. This will easily cause psychological pressure and burden, and lead to cultural shock and adaptation problems. Furnham and Tresize (1983) pointed out that foreign students encounter difficulties that can be seen in three categories: (i) Lifestyle issues: racial discrimination, language problems, adaptation problems, dietary problems, economic stress; (ii) Emotional issues: loneliness, emotional independence, and so on; (iii) Academic issues: subjects related to the professional courses.

When foreign students participate in classroom learning or daily conversation, they often misunderstand the dialogue, especially when most universities in Taiwan teach in Mandarin. Furthermore, local students also speak

48 Consortia Academia Publishing (A partner of Network of Professional Researchers and Educators) 
A study on the relationship between academic adjustment and global mobility of foreign students in Taiwan

in Mandarin most of the time. With Mandarin being spoken predominantly in the classroom, it is very difficult for foreign students to understand in class. Furthermore, Wei, Heppner, Mallen, Ku, Lian, and Wu (2007) indicate that International students from China often do not actively seek counseling and psychological assistance, even if they encounter some difficulties. Liao, Wei, Ku, Russell, and Mallinckrodt (2008) conducted this research on 354 foreign students from China, India, Korea, Taiwan, and Hong Kong. The study finds that schools can hire bilingual counselors to increase the frequency of consulting services used by Asian students.

Global mobility plays a key role in helping the right talents move from one country to another (McDonnell, Lamare, Gunnigle, \& Lavelle, 2010). According to United Nations statistics in 2005, nearly 190 million people worldwide have left their home countries, showing that moving away to other places to work or living in exotic cultures have become trends that young people must face in the future. "Global Mobility" has become an important ability of the modern youth in order to survive in the global village (Lin, 2016). Global mobility must appreciate and accommodate different perspectives and interpersonal dynamics, integrate multiple disciplines, work across cultures, and interpret diverse and multiple streams of information (Aguirre, Hewlett, \& Post, 2009). The international movement of talent can facilitate the mastery of foreign languages, expand professional networks, and broaden international perspectives. Students pursuing international competitiveness should be able to make a step in their future career development.

According to the Ministry of Education (2016) on "The project on promoting young students' global mobility”, global mobility was categorized into four components: communication, adaptability, Professional Competence, and execution. This study attempts to examine the impact of global mobility (Communication, Adaptability, Professional Competence, and Execution). The definitions are as follow:

> Communication - Communication is defined as sharing ideas and knowledge with others from countries all over the world. An understanding of others' viewpoints and feelings may be enhanced by an understanding of their background and culture.

> Adaptability - In the context of globalization, adaptability refers to an efficient communication with others and recognizing heterogeneous societies and cultures. This adaptability can also be enhanced by a strong sense of self-awareness and a clear understanding how one relates to others.

>Professional competence - Professional competence is referred to as specialty knowledge, attitude, and skills required to work in a specialized field. Foreign students are more likely to demonstrate professional knowledge according to international standards and cross-border applications.

$>$ Execution - A good plan is important; moreover, a good execution is also critical. Many excellent plans fail because not everyone is fully committed to the execution. Foreign students have the ability to work in other countries.

\section{Methods}

\subsection{Participants}

There were 316 foreign students selected as volunteers in this study, with 191 males and 125 females. A total of 410 questionnaires were distributed to foreign students in this study. Adopting this approach, a final sample of 352 respondents was achieved. The overall response rate is $85.8 \%(\mathrm{~N}=352)$. After the elimination of 36 questionnaires that had an excessive amount of missing data, the final sample consists of 316 respondents. According to the analytic results of Table 3 descriptive statistics, the following results are summarized:

Gender - The number of male and female participants was distributed as shown in Table 3 with 191 males, representing $60.4 \%$ of the valid sample; 125 females, representing $39.6 \%$ of the valid sample. According to the statistical results, the ratio of foreign students in male and female is very different, with the number of males 
Huang, C.-Y., \& Lin, S.-L.

much higher than that of females.

Table 3

Descriptive Statistics

\begin{tabular}{|c|c|c|c|c|}
\hline Variables & Items & & Numbers $(n)$ & Percentage $(\%)$ \\
\hline \multirow[t]{3}{*}{ Gender } & Male & & 191 & $60.4 \%$ \\
\hline & Female & & 125 & $39.6 \%$ \\
\hline & & Total & 316 & $100 \%$ \\
\hline \multirow[t]{6}{*}{ Age } & Under 20 & & 29 & $9.2 \%$ \\
\hline & Between 21-25 & & 104 & $32.9 \%$ \\
\hline & Between 26-30 & & 124 & $39.2 \%$ \\
\hline & Between 31-35 & & 15 & $4.7 \%$ \\
\hline & Above 36 & & 44 & $13.9 \%$ \\
\hline & & Total & 316 & $100 \%$ \\
\hline \multirow[t]{8}{*}{ Nationality } & Indonesia & & 161 & $50.9 \%$ \\
\hline & The Philippines & & 6 & $1.9 \%$ \\
\hline & Thailand & & 7 & $2.2 \%$ \\
\hline & Malaysia & & 2 & $0.6 \%$ \\
\hline & Vietnam & & 90 & $28.5 \%$ \\
\hline & Myanmar & & 2 & $0.6 \%$ \\
\hline & Others & & 48 & $15.2 \%$ \\
\hline & & Total & 316 & $100 \%$ \\
\hline \multirow[t]{4}{*}{ Enrollment Status } & Undergraduate & & 41 & $13 \%$ \\
\hline & Master & & 238 & $75.3 \%$ \\
\hline & Doctoral Degree & & 37 & $11.7 \%$ \\
\hline & & Total & 316 & $100 \%$ \\
\hline \multirow[t]{6}{*}{ System of School } & Exchange Student & & 11 & $3.5 \%$ \\
\hline & Research Student & & 305 & $96.5 \%$ \\
\hline & Industry-Academia Collaboration & & 0 & $0 \%$ \\
\hline & Program for International Student & & & \\
\hline & Others & & 0 & $0 \%$ \\
\hline & & Total & 316 & $100 \%$ \\
\hline \multirow[t]{12}{*}{ College } & Liberal Arts & & 51 & $16.1 \%$ \\
\hline & Art & & 22 & $7 \%$ \\
\hline & Communication & & 3 & $0.9 \%$ \\
\hline & Education & & 2 & $0.6 \%$ \\
\hline & Medicine & & 1 & $0.3 \%$ \\
\hline & Science and Engineering & & 160 & $50.6 \%$ \\
\hline & Foreign Language \& Literatures & & 13 & $4.1 \%$ \\
\hline & Law & & 0 & $0 \%$ \\
\hline & Management & & 63 & $19.9 \%$ \\
\hline & Design & & 1 & $0.3 \%$ \\
\hline & Others & & 0 & $0 \%$ \\
\hline & & Total & 316 & $100 \%$ \\
\hline \multirow{4}{*}{$\begin{array}{l}\text { The Fluency of } \\
\text { Mandarin }\end{array}$} & Excellent & & 39 & $12.3 \%$ \\
\hline & Intermediate & & 121 & $38.3 \%$ \\
\hline & Beginning & & 156 & $49.4 \%$ \\
\hline & & Total & 316 & $100 \%$ \\
\hline \multirow{3}{*}{$\begin{array}{l}\text { The experiences of } \\
\text { Study Abroad }\end{array}$} & $\ulcorner$ Yes $\lrcorner$ & & 112 & $35.4 \%$ \\
\hline & $\ulcorner\mathrm{No}\lrcorner$ & & 204 & $64.6 \%$ \\
\hline & & Total & 316 & $100 \%$ \\
\hline \multirow{3}{*}{$\begin{array}{l}\text { A Foreign Citizen of } \\
\text { Chinese Origin }\end{array}$} & $\ulcorner$ Yes $\lrcorner$ & & 15 & $4.7 \%$ \\
\hline & $\ulcorner\mathrm{No}\lrcorner$ & & 301 & $95.3 \%$ \\
\hline & & Total & 316 & $100 \%$ \\
\hline \multirow[t]{3}{*}{ School } & National University & & 221 & $69.9 \%$ \\
\hline & Private University & & 95 & $30.1 \%$ \\
\hline & & Total & 316 & $100 \%$ \\
\hline
\end{tabular}

50 Consortia Academia Publishing (A partner of Network of Professional Researchers and Educators) 
A study on the relationship between academic adjustment and global mobility of foreign students in Taiwan

Table 3 ... continued

\begin{tabular}{llcc}
\hline \multicolumn{1}{c}{ Variables } & \multicolumn{1}{c}{ Items } & Numbers $(n)$ & Percentage $(\%)$ \\
\hline The Reason for Study & Scholarship from Taiwan & 165 & $52.2 \%$ \\
Abroad in Taiwan & Scholarship from your country & 46 & $14.6 \%$ \\
& The academic reputation is high. & 121 & $38.3 \%$ \\
& The tuition is cheaper & 108 & $34.2 \%$ \\
& Others & 77 & $24.4 \%$ \\
\hline Your Financial Supply & Parents & 75 & $23.7 \%$ \\
for Study Abroad & Having Part time job & 206 & $65.2 \%$ \\
& Others & 39 & $12.3 \%$ \\
\hline
\end{tabular}

Age - In terms of age, out of 316 foreign students in the valid sample, 29 participants were under the age of 20, representing $9.2 \%$ of the valid sample; 104 participants were aged 21-25, representing $32.9 \%$. 124 participants were aged 26-30, representing $39.2 \%$ of the valid sample, the largest group. The number of 31-35-year olds was 15 , representing $4.7 \%$ of the valid sample and is the smallest group. The number of people over 36 years of age was 44 , representing $13.9 \%$ of the valid sample. According to the statistical results, most of the foreign students studying in Taiwan are 21-25 years old and 26-30 years old, forming the largest group.

Nationality - According to the nationality analysis, out of 316 foreign students in all valid samples, 161 were from Indonesia, representing $50.9 \%$ of the valid sample, and is the largest number in terms of nationality. The number of foreign students in Malaysia was only 2 participants, representing $0.6 \%$ of the valid sample; the number of foreign students in Vietnam was 90 , representing $28.5 \%$ of the valid sample. According to the statistics, most participants were from Indonesia and then Vietnam. The least participants came from Malaysia and Myanmar.

Enrollment - According to the foreign students' analysis, the number of students studying in the university department was 41 , accounting for $13 \%$ of the valid sample; the number of students studying for a master's degree was 238, representing $75.3 \%$ of the valid sample; and the number of doctoral students was 37 , representing $11.7 \%$ of the valid sample; the lowest number of participants. Statistical analysis revealed that the majority of foreign students chose to come to Taiwan to study for a master's degree, though only a few foreign students chose to come to Taiwan to study for a doctorate.

System of school - According to the analysis of the question 5 on the personal background, the number of exchange students was 11 , accounting for $3.5 \%$ of the valid sample. The number of foreign students studying for an advanced degree was 305 , accounting for $96.5 \%$ of the valid sample, it is the largest group. Statistical analysis reveals that most foreign students who come to Taiwan will choose to study for a degree.

College - According to the analysis of the colleges chosen by foreign students, the College of Liberal Arts was 51 , accounting for $16.1 \%$ of the valid sample; the College of Art was 22, accounting for $7 \%$ of the valid sample, the College of Communication was 3, accounting for $0.9 \%$ of the valid sample, the College of Education was 2 , accounting for $0.6 \%$ of the valid sample, and the College of medical had only 1 foreign student majoring in the College of Health Sciences and Technology, accounting for $0.3 \%$ of valid samples. 160 participants came from the College of Science and Engineering, accounting for $50.6 \%$ of valid samples.

Fluency in Mandarin - The foreign students' Mandarin fluency was analyzed, accounting for 39 foreign students with Mandarin proficiency that is $12.3 \%$ of the valid sample. While the number of foreign students with intermediate Mandarin was 121, accounting for $38.3 \%$ of the valid sample, the number of foreign students with poor Mandarin was 156 , accounting for $49.4 \%$ of the valid sample. Statistical analysis revealed that only a few foreign students are adept in Mandarin proficiency.

Experiences of study abroad - The answer of "Yes" was 112; representing $35.4 \%$ of the valid sample, and the answer was "No" to 204 , accounting for $64.6 \%$ of the valid sample. 
Are you a foreign citizen of Chinese origin - Fifteen foreign students, representing $4.7 \%$ of the valid sample. There are 301 foreign students without Chinese origin, accounting for $95.3 \%$ of the valid sample. Most of the foreign students are not of Chinese origin, and only a few of 15 foreign students are of Chinese origin.

School - The number of students attending national universities was 221, representing $69.9 \%$ of the valid sample. The number of students attending private universities was 95 , accounting for $30.1 \%$ of the valid sample. Most of the foreign students come from national universities.

The reason for studying abroad in Taiwan - Most of the foreign students studying in Taiwan received a scholarship subsidy from our government, 165 selected this as the main motivation for studying in Taiwan, accounting for $52.2 \%$ of the valid sample. However, only 46 were quoted as studying abroad on "scholarships offered by their own countries".

The financial supply for studying abroad in Taiwan - The statistical analysis from Table 3 statistical shows 75 foreign students study in Taiwan with economic resources provided by their parents, accounting for $23.7 \%$ of the valid sample. However, 206 foreign students indicated that they work part-time job to support their lifestyle in Taiwan.

\subsection{Measurement}

The measurement used in this research is based on previous research and literature review. The first part of questionnaire is a personal background survey, and was adopted from the Research Development and Evaluation Commission "Recruiting Overseas Chinese Students to Study in Taiwan (II): Living Adaptation, Students Counseling and Promotion Tactics" (2008). The second part of questionnaire was adopted from Ching, Lien, and Chao's (2014) Short-term Study Abroad Situational Change Survey (SSCS) in order to investigate academic adjustment, problem solving strategies, and service satisfaction. The third part of the questionnaire was based on the Ministry of Education (2016) on "The project on promoting young students' global mobility" and Chen (2017) on "A Study on the Effect of Attending International Volunteering on College Student's International Volunteering". The researcher eliminates several redundant items and use Likert five-point scales anchored by Strongly agree (5 point) to strongly disagree (1 point).

Data was collected and calculated by SPSS (Statistical Package for the Social Science). The results of the statistical analysis were used to investigate the foreign students' academic adjustment and global mobility. For the quantitative data, a total of 316 foreign students participated in the survey and filled out an online questionnaire regarding the first part "Personal Background"; the second part "Academic Adjustment and the Strategy of Problem Solving"; the third part global mobility, communication, adaptability, professional, and execution.

The strength of the findings in this study is dependent upon the extent to which the instrument provides reliable measures. For purpose of this research, the Cronbach's Alpha coefficient is used to separately assess the reliability of the scales adopted in this study. Coefficient alpha for the four dimensions was found to be over 0.7 , a reasonable level of acceptance for the group of items.

\section{Table 4}

Cronbach's Alpha coefficient of the questionnaire

\begin{tabular}{lc}
\hline \multicolumn{1}{c}{ Dimension } & Cronbach's $\alpha$ Coefficient \\
\hline Academic Adjustment & .886 \\
The Strategy of Problem Solving & .719 \\
Service Satisfaction & .930 \\
Global Mobility & .950 \\
\hline
\end{tabular}




\subsection{Data analysis}

Descriptive statistics - Descriptive statistics was used to illustrate means, standard deviations, percentages, frequencies, and distribution of samples. Descriptive analysis was performed to illustrate the participants' overall responses to the questionnaire.

Independent sample t-test - An independent sample t-test was used to investigate foreign students' background variables, such as, gender, the experiences of study abroad.

One-way analysis of variance - One-way analysis of variance was used to investigate age, and enrollment status in order to analyze the different personal background between the academic adjustment and problem solving strategies.

Pearson Correlation - Pearson Correlation coefficient proving the relationships between independent variables and dependent variables was applied to examine significant relationship between the foreign students' academic adjustment and problem solving strategies, service satisfaction, and global mobility.

\section{Result and discussions}

The results of the investigation in this study provide a number of unique contributions. The respective findings carry important implications, all of which are discussed below.

\subsection{The analyses of the Foreign Students' Academic Adjustment}

First of all, an "independent sample t-test" was created in order to investigate the differences in gender, and past experiences in studying abroad. Moreover, the researcher compared the differences in age, and enrollment status through "one-way analysis of variance".

\section{Academic adjustment for foreign students of different genders}

According to Table 5, there are significant differences in the peer relationship between males and females. In the peer relationship, females are more emotional, and they are more likely to feel troubled and care about interpersonal problems in their lives.

\section{Table 5}

Academic adjustment for foreign students of different genders: Independent sample t-test

\begin{tabular}{|c|c|c|c|c|}
\hline \multirow{2}{*}{ Items } & Male $n=191$ & Female $n=125$ & \multirow{2}{*}{$t$} & \multirow{2}{*}{ Sig. } \\
\hline & $M(S D)$ & $M(S D)$ & & \\
\hline Understanding lectures \& Taking notes in class & $2.88(1.521)$ & $2.67(.878)$ & 1.574 & .116 \\
\hline Doing group discussion \& doing homework & $2.42(1.495)$ & $2.67(.905)$ & -1.835 & .067 \\
\hline $\begin{array}{l}\text { Struggling with the interaction with the } \\
\text { professors or faculty }\end{array}$ & $2.79(1.528)$ & 2.43(.953) & 2.56 & .011 \\
\hline $\begin{array}{l}\text { Struggling with the interpersonal relationship } \\
\text { with my classmates }\end{array}$ & $2.47(1.507)$ & $2.91(1.225)$ & -2.852 & $.005 * *$ \\
\hline
\end{tabular}

\section{Academic adjustment for foreign students who have the experiences of study abroad}

According to Table 6, the foreign students who have past overseas experience before coming to Taiwan are better at understanding lectures, taking notes, and interacting with faculty. There are significant differences between those who have overseas experience and those who do not. 
Huang, C.-Y., \& Lin, S.-L.

\section{Table 6}

Academic adjustment for foreign students who have the experiences of study abroad: Independent sample t-test

\begin{tabular}{|c|c|c|c|c|}
\hline Items & $\frac{\text { Yes } n=112}{M(S D)}$ & $\frac{\text { No } n=204}{M(S D)}$ & $t$ & Sig. \\
\hline Understanding lectures \& Taking notes in class & $2.48(0.910)$ & $2.98(1.454)$ & -3.703 & $.000 * * *$ \\
\hline Doing group discussion \& doing homework & $2.54(1.222)$ & $2.51(1.341)$ & .234 & .815 \\
\hline $\begin{array}{l}\text { Struggling with the interaction with the } \\
\text { professors or faculty }\end{array}$ & $2.18(0.862)$ & $2.91(1.481)$ & -5.524 & $.000 * * *$ \\
\hline $\begin{array}{l}\text { Struggling with the interpersonal relationship } \\
\text { with my classmates }\end{array}$ & $2.42(1.242)$ & $2.77(1.492)$ & -2.227 & $.0027 * *$ \\
\hline
\end{tabular}

\section{Academic adjustment for foreign students of different ages and enrollment status}

Foreign students of different ages have significant differences in academic adjustment. Foreign students of older ages have fewer academic problems. Foreign students aged between 26 and 30 years old have more academic problems and face more difficulties.

\section{Table 7}

Academic adjustment for foreign students of different ages and enrollment status: One-way analysis of variance

\begin{tabular}{|c|c|c|c|c|c|c|}
\hline $\begin{array}{l}\text { Background } \\
\text { variables }\end{array}$ & Group & Numbers & Mean & $S D$ & $F$ & Scheffé \\
\hline \multirow[t]{6}{*}{ Ages } & a. Under 20 & 29 & 2.285 & 0.664 & 3.541 & $a>d$ \\
\hline & b. Between 21-25 & 104 & 2.625 & 1.129 & & $b>d$ \\
\hline & c. Between 26-30 & 124 & 2.835 & 1.415 & & $c>d$ \\
\hline & d. Between 31-35 & 15 & 1.833 & 0.397 & & $e>d$ \\
\hline & e. Above 36 & 44 & 2.739 & 0.578 & & \\
\hline & Total & 316 & 2.654 & 1.162 & & \\
\hline Enrollment & a. Undergraduate & 41 & 2.342 & 0.897 & 19.554 & $a>c$ \\
\hline \multirow[t]{3}{*}{ Status } & b. Master Degree & 238 & 2.856 & 1.165 & & $b>c$ \\
\hline & c. Doctoral Degree & 37 & 1.703 & 0.812 & & \\
\hline & Total & 316 & 2.654 & 1.162 & & \\
\hline
\end{tabular}

\subsection{The analyses of the foreign students' global mobility}

Referring to Table 8, several differences can be observed with respect to the global mobility between male and female. There are four indicators to represent the global mobility, including the strength of specialty, the skill level of communication, the ability of adapting a new environment, and the capability of applying the specialty in the future. Two significant differences in the skill level of communication and the strength of specialty are noticeable between male and female. The male is skilled in communication and has a better performance in conveying or expressing thoughts than the female. Furthermore, the male is much confident and competent when applying the specialties in the future career.

\section{Table 8}

Global mobility for foreign students of different ages: Independent sample t-test

\begin{tabular}{lccccc}
\hline \multirow{2}{*}{ Items } & Male $n=191$ & Female $n=125$ & \multirow{2}{*}{$t$} & \multirow{2}{*}{ Sig. } \\
\cline { 2 - 3 } & $\mathrm{M}(\mathrm{SD})$ & $\mathrm{M}(\mathrm{SD})$ & & 3.878 & $.000^{* * * *}$ \\
Communication & $3.966(.808)$ & $3.632(.648)$ & & 323 \\
Adaptability & $4.141(.903)$ & $4.203(.734)$ & & -0.640 & .523 \\
Professional & $3.963(1.126)$ & $3.540(.945)$ & & 3.478 & $.001^{* * *}$ \\
Execution & $3.808(.988)$ & $3.779(.514)$ & & 0.346 & .730 \\
\hline
\end{tabular}


A study on the relationship between academic adjustment and global mobility of foreign students in Taiwan

According to Table 9, there are significant differences in global mobility between students' overseas experience, especially in communication. Those who have overseas experience are good at adapting to local lifestyles and also like to make foreign friends, as well as have a good relationship with locals.

Table 9

Global mobility for foreign students of the overseas experience: Independent sample t-test

\begin{tabular}{|c|c|c|c|c|}
\hline \multirow{2}{*}{ Items } & Yes $n=112$ & No $n=204$ & $t$ & Sig. \\
\hline & $M(S D)$ & $M(S D)$ & $l$ & \\
\hline Communication & $3.761(.652)$ & $3.874(.819)$ & -1.253 & .211 \\
\hline Adaptability & $4.630(.387)$ & 3.911(.909) & 9.800 & $.000 * * *$ \\
\hline Professional & $3.906(.715)$ & $3.735(1.228)$ & 1.563 & .119 \\
\hline Execution & $3.856(.342)$ & $3.764(1.004)$ & 1.186 & .236 \\
\hline
\end{tabular}

According to Table 10, foreign students aged below 20 years old have poor global mobility and face more difficulties. Foreign students with intermediate Mandarin abilities show a higher level of global mobility. Foreign students, who have poor Mandarin abilities, also show poor global mobility.

\section{Table 10}

Global mobility for foreign students of different ages and the fluency of Mandarin: One-way analysis of variance

\begin{tabular}{|c|c|c|c|c|c|c|}
\hline $\begin{array}{c}\text { Background } \\
\text { variables }\end{array}$ & Group & Numbers & Mean & $S D$ & $F$ & Scheffé \\
\hline \multirow{6}{*}{ Ages } & a. Under 20 & 29 & 4.061 & 0.163 & \multirow[t]{6}{*}{4.866} & $\mathrm{~d}>\mathrm{a}$ \\
\hline & b. Between 21-25 & 104 & 4.003 & 0.406 & & $d>b$ \\
\hline & c. Between 26-30 & 124 & 3.833 & 1.017 & & $d>c$ \\
\hline & d. Between 31-35 & 15 & 4.463 & 0.387 & & $\mathrm{~d}>\mathrm{e}$ \\
\hline & e. Above 36 & 44 & 3.639 & 0.583 & & \\
\hline & Total & 316 & 3.913 & 0.738 & & \\
\hline \multirow{4}{*}{$\begin{array}{l}\text { The fluency } \\
\text { of Mandarin }\end{array}$} & a. Excellent & 39 & 3.815 & 0.181 & \multirow[t]{4}{*}{10.483} & $\mathrm{~b}>\mathrm{a}$ \\
\hline & b. Intermediate & 121 & 4.146 & 0.490 & & $b>c$ \\
\hline & c. Beginning & 156 & 3.756 & 0.919 & & \\
\hline & Total & 316 & 3.913 & 0.738 & & \\
\hline
\end{tabular}

\subsection{The relationship between academic adjustment, solving problems, service satisfaction, and global mobility}

There are significant differences among different genders, in solving problems, and service satisfaction of participants. Females suffer more from more academic adjustments and problems. In addition, there are negative correlations between the foreign students' academic adjustment and global mobility. The more problems the foreign students have, the less service satisfaction their schools receive. When foreign students suffer from more academic adjustments, they don't know how to ask for help.

\section{Table 11}

Four dimensions for foreign students of different genders: Independent sample t-test

\begin{tabular}{|c|c|c|c|c|}
\hline \multirow{2}{*}{ Dimensions } & Male $n=191$ & Female $n=125$ & \multirow{2}{*}{$t$} & \multirow{2}{*}{ Sig. } \\
\hline & $M(S D)$ & $M(S D)$ & & \\
\hline Academic Adjustment & $2.643(1.348)$ & $2.672(.803)$ & -.242 & .809 \\
\hline The Strategy of Problem Solving & $3.606(1.110)$ & $3.324(.805)$ & 2.613 & $.009 * *$ \\
\hline Service Satisfaction & $3.653(1.171)$ & $3.382(.906)$ & 2.315 & $.021 *$ \\
\hline Global Mobility & $3.960(.854)$ & $3.841(.507)$ & 1.546 & .123 \\
\hline
\end{tabular}

Note. ${ }^{*} p<.05{ }^{* *} p<.01$.

There are positive correlations between the foreign students' problem-solving capacity and service satisfaction. When foreign students are able to ask the school for assistance, they will have shown higher service satisfaction toward their schools. The school needs to let foreign students know how to use the school's 
Huang, C.-Y., \& Lin, S.-L.

counseling and resources.

\section{Table 12}

Analysis of four dimensions: Pearson correlation

\begin{tabular}{lcccc}
\hline \multicolumn{1}{c}{ Dimensions } & $\begin{array}{c}\text { Academic } \\
\text { Adjustment }\end{array}$ & $\begin{array}{c}\text { The Strategy of } \\
\text { Problem Solving }\end{array}$ & $\begin{array}{c}\text { Service } \\
\text { Satisfaction }\end{array}$ & Global Mobility \\
\hline Academic Adjustment & 1 & $-.502^{* * *}$ & $-.630^{* * *}$ & $-.504 * * *$ \\
The Strategy of Problem Solving & $-.502^{* * *}$ & 1 & $.886^{* * *}$ & $.561^{* * *}$ \\
Service Satisfaction & $-.630^{* * *}$ & $.886^{* * *}$ & 1 & $.500^{* * *}$ \\
Global Mobility & $-.504 * * *$ & $.561 * * *$ & $.500^{* * *}$ & 1 \\
\hline
\end{tabular}

\section{Conclusions and future research}

Based on the results of this study, the main findings are summarized as follows:

\section{The analyses of the foreign students' academic adjustment}

$>$ There are significant differences in the peer relationship between male and female. In peer relationships, females are more emotional, and they are more likely to feel troubled and care about the interpersonal problems in their lives.

$>\quad$ Foreign students, who have overseas experiences before coming to Taiwan, are better at understanding lectures, taking notes, and interacting with faculty. There are significant differences between those who have prior overseas experience and those who do not.

$>\quad$ Foreign students of different age groups have significant differences in academic adjustment. Foreign students in older age groups have fewer academic problems. Foreign students aged between 26 and 30 years old have more academic problems and face more difficulties.

\section{The analyses of the foreign students' global mobility}

$>\quad$ There are significant differences in the level of global mobility between different genders, especially in the areas of communication and in professional. There are four indicators to represent the global mobility, including the strength of specialty, the skill level of communication, the ability of adapting a new environment, and the capability of applying the specialty in the future. Two significant differences in the skill level of communication and the strength of specialty are noticeable between male and female. The male is skilled in communication and has a better performance in conveying or expressing thoughts than the female. Furthermore, the male is much confident and competent when applying the specialties in the future career.

$>\quad$ Those that have past overseas experience are more capable of adapting to local lifestyles, like to make foreign friends and are able to build good relationships with locals.

$>$ Foreign students aged below 20 years old demonstrate poor global mobility levels and face more difficulties.

The relationship between academic adjustment, solving problems, service satisfaction, and global mobility of foreign students

$>\quad$ There are significant differences among different gendered participants in problem solving and the service satisfaction. Females suffer from more academic adjustments and problems.

$>\quad$ There are negative correlations between foreign students' academic adjustments and global mobility. The more problems that foreign students have, the less service satisfactions the schools receive. When foreign students suffer from academic adjustments, they don't know how to ask for help. 
A study on the relationship between academic adjustment and global mobility of foreign students in Taiwan

$>\quad$ There are positive correlations between the foreign students' problem-solving abilities and service satisfaction. When the foreign students know how to ask their school for assistance, they will have report a higher service satisfaction toward their school. Schools need to let foreign students know how to use school counseling resources.

Although these educational issues are complicated, we still have an opportunity to move forward quickly and responsibly, to work together and create a better future. In future studies, we will further analyze the effectiveness of professional development in teaching strategies through different teaching strategies that respond to different student communities. These ideas need to further evolve, in response to changing imperatives. According to the results of this study, the suggestions and applications below are put forward as a reference for educational administration agencies, schools, and further studies in the future.

Acknowledgement: This paper is part of a Masteral thesis accomplished in 2020 for the Graduate Institute of Educational Leadership and Development at the Fu Jen Catholic University in Taiwan.

\section{References}

Aguirre, D., Hewlett, S., \& Post, L. (2009). Global talent innovation: Strategies for breakthrough performance (pp. 1-25). San Francisco: Booz and Company.

Ching, G. S., Lien, W.C., \& Chao, P.-C. (2014). Developing a scale to measure the situational changes in short-term study abroad programs. International Journal of Research Studies in Education, 3(5), 53-71. https://doi.org/10.5861/ijrse.2014.771

Enders, J. (2004). Higher education, internationalisation, and the nation-state: Recent developments and challenges to governance theory. Higher Education, 47(3), 361-382. https://doi.org/10.1023/B:HIGH.0000016461.98676.30

Furnham, A., \& Tresize, L. (1983). The mental health of foreign Students. Social Science and Medicine, 17, 365-370. https://doi.org/10.1016/0277-9536(83)90239-3

Lin, M. D. (2016). The international mobility spectrum: Wise and practical actions. Journal of Education Research, 271, 4-16.

McDonnell, A., Lamare, R., Gunnigle, P., \& Lavelle, J. (2010). Developing tomorrow's leaders: Evidence of global talent management in multinational enterprises. Journal of World Business, 45, 150-160. https://doi.org/10.1016/j.jwb.2009.09.015

Ministry of Education, Department of International and Cross-Strait Education Academic, Republic of Taiwan. (2019). Department of the National College of Education overseas students living information network. Retrieved from https://ois.moe.gov.tw/WEB/fs/html/StatisticSearchD.html

Ministry of Education, Republic of Taiwan. (2019). MOE unveils measures to support New Southbound Policy. Retrieved from https://nspp.mofa.gov.tw/nsppe/content_tt.php?post=102472

Ministry of Education, Republic of Taiwan. (2019). Statistics. Retrieved from https://depart.moe.edu.tw/ED4500/

Ministry of the Interior, Republic of Taiwan. (2019). Statistics. Retrieved from https://www.moi.gov.tw/stat/english/node.aspx?sn=7132

National Academy for Educational Research. (2016). The Republic of China education yearbook 2016. Retrieved from https://www.naer.edu.tw/files/15-1000-13943,c1310-1.php

Research Development and Evaluation Commission, Executive Yuan. (2008). Recruiting overseas Chinese students to study in Taiwan (II): Living adaptation, students counselling and promotion tactics. Taipei City: Center for Educational Resources and Publishing.

Vickers, P., \& Bekhradnia, B. (2007). The economic costs and benefits of international students. Oxford: Higher Education Policy Institute.

Wei, M., Heppner, P. P., Mallen, M., Ku, T.Y., Liao, K. Y. H., \& Wu, T. F. (2007). Acculturative stress, perfectionism, years in U.S. and depression among Chinese international students. Journal of 
Huang, C.-Y., \& Lin, S.-L.

Counseling Psychology, 54(4), 385-394. https://doi.org/10.1037/0022-0167.54.4.385

Wei, M., Ku, T.-Y., \& Russell, D. W. (2008). Moderating effects of three coping strategies and self-esteem on perceived discrimination and depressive symptoms: A minority stress model for Asian international students. Journal of Counseling Psychology, 55(4), 451-461. https://doi.org/10.1037/a0012511

Yang, A. H. (2017). Revisiting Taiwan's new southbound policy: Agenda, networks and challenges. Issues and Studies, 56(1), 123-143. 